\title{
Produção e memória do Laboratório de Programação Gráfica da FAU USP: bases para criação de ficha catalográfica
}

\author{
Production and memory of the Graphic Programming Laboratory at FAU USP: \\ bases for creating a catalog sheet
}

Vinícius de Souza Lima, Clice Toledo de Sanjar Mazzilli

catalogação, metadados, design gráfico

Esta pesquisa insere-se em projeto maior que visa resgatar a produção editorial do Laboratório de Programação Gráfica da FAU USP de modo a tornar acessível um acervo relevante ao estudo do design gráfico. Para tanto, realiza a observação, análise e organização sistemática de peças gráficas e editoriais produzidas pela seção técnica. No intento de tornar essa produção acessível, criam-se fichas catalográficas digitais unitárias, agrupadas e organizadas em um banco de dados aberto à consulta pública, estruturado com base em princípios do design de informação e da organização de dados.

cataloguing, metadata, graphic design

This research is part of a larger project that aims to rescue the editorial production of the Laboratory of Graphic Programming at FAU USP in order to make accessible a collection relevant to the study of graphic design. To this end, it performs the observation, analysis and systematic organization of graphic and editorial pieces produced by the technical section. In an attempt to make this production accessible, unitary digital catalog sheets are created, grouped and organized in a database open to public consultation, structured based on the principles of information design and data organization.

\section{Introdução}

Fundado na década de 1970, o Laboratório de Programação Gráfica (LPG) assume a responsabilidade de produzir materiais gráficos destinados a ensino, pesquisa, extensão e administração da Faculdade de Arquitetura e Urbanismo da USP. Atualmente denominado Seção Técnica de Produção Editorial (STPROED), o laboratório dá suporte a todos os setores da faculdade, desenvolvendo desde o projeto gráfico até impressão e acabamentos do material, além de, eventualmente, oferecer apoio às demais unidades da USP.

Com cerca de cinquenta anos de existência, a seção técnica tem grande importância na consolidação da identidade visual e editorial da FAU USP, além de ter tornado possível manifestações do corpo discente por meio da produção gráfica de inúmeros projetos estudantis independentes. Os impressos aqui estudados são, portanto, o resultado de quase cinco décadas de atividade do laboratório e materializam o desenvolvimento

Anais do $10^{\circ} \mathrm{CIDI}$ e $10^{\circ} \mathrm{CONGIC}$

Kelli C.A.S. Smythe, Rafael de Castro Andrade (orgs.)

Sociedade Brasileira de Design da Informação - SBDI

Curitiba | Brasil | 2021
Proceedings of the $10^{\text {th }} \mathrm{CIDI}$ and $10^{\text {th }}$ CONGIC

Kelli C.A.S. Smythe, Rafael de Castro Andrade (orgs.)

Sociedade Brasileira de Design da Informação - SBDI Curitiba | Brazil | 2021 
conceitual e tecnológico da produção da faculdade, permitindo-nos compreender a história da FAU USP por meio de sua produção gráfica.

Tendo em vista a dificuldade em organizar e acessar todo esse material, esta pesquisa investigou ciências voltadas à sistematização de dados, com o intuito de criar um repositório digital online, utilizando ferramentas tecnológicas que possibilitem uma catalogação detalhada das peças e permitam que as mesmas sejam consultadas de forma simples por qualquer usuário interessado.

\section{Objetivos}

1. Levantar formas de organização e sistematização de acervos, levando em conta fundamentos da arquivologia, biblioteconomia e áreas correlatas;

2. Definir um conjunto de dados relevantes ao estudo do design gráfico, pontuando aspectos relacionados ao conceito, linguagem gráfica e materialidade das peças;

3. Tornar a produção editorial da FAU USP acessível aos interessados, por meio da criação de um banco de dados público;

4. Desenvolver um manual de catalogação que dê suporte a futuros pesquisadores para a continuidade da inserção de dados.

\section{Metodologia}

A pesquisa teve como premissa o uso da plataforma Omeka S para criação do banco de dados. Este é o sistema adotado para catalogação dos acervos iconográficos da Faculdade. A fim de compreender o funcionamento da ferramenta Omeka $S$ e ponderar sobre a melhor forma de utilizá-la em favor dos objetivos da pesquisa, parte-se inicialmente do reconhecimento da mesma, bem como de suas diretrizes técnicas. Isso se dá em termos teóricos e práticos, no intuito de mapear as potencialidades e limitações do sistema.

Com base nas informações levantadas, aprofunda-se na discussão referente à construção das fichas que deverão identificar as peças gráficas do acervo. A partir da análise do sistema Dublin Core Metadata Initiative (DCMI), desenvolve-se uma ficha catalográfica que atende os padrões estabelecidos internacionalmente e, ao mesmo tempo, dá atenção aos dados referentes ao design das peças. Ao explorar o elemento de metadado intitulado "Descrição", estrutura-se uma "Ficha técnica" com informações pertinentes ao projeto e produção do material.

Por fim, analisou-se o resultado das discussões e das atividades referentes ao desenvolvimento das fichas, com o intuito de organizar esses resultados em um produto editorial que consolida e apresenta o método de catalogação estabelecido. O Manual de catalogação do LPG sintetiza o detalhamento das fichas catalográficas e as organiza explorando soluções formais que facilitem sua compreensão. 


\section{Resultados e Discussão}

\section{Embasamento teórico}

O primeiro passo foi buscar informações referentes ao funcionamento do sistema Omeka S. Trata-se de uma plataforma de acesso livre, destinada a gerenciar coleções digitais. Mesmo sendo voltada a bibliotecas, busca atender também a outros profissionais de informação que atuam na gestão de coleções digitais em várias áreas. (SHINTAKU et al., p. 11, 2018).

Costuma-se utilizar sistemas de metadados na criação de coleções digitais, já que o uso desses padrões possibilita aos sistemas de informação e de gestão do conhecimento a integração e o compartilhamento de recursos e aplicações. (ALVES e SOUZA, p. 22, 2007)

O sistema utilizado neste caso é o DCMI (Dublin Core ${ }^{\mathrm{TM}}$ Metadata Initiative). O DCMI tem como principal missão criar mecanismos que facilitem a recuperação de recursos na Internet, utilizando-se de padrões de metadados. Uma das principais características do DCMI é a abertura à participação de qualquer pessoa ou instituição interessada em buscar um consenso mínimo no desenvolvimento de vocabulários de metadados. (GRÁCIO, p. 42, 2002)

Esse sistema apresenta 15 elementos de metadados básicos. Segundo o Dublin Core (2014), estes elementos podem ser descritos como na tabela a seguir:

Tabela 1: Elementos de metadados DCMI

\begin{tabular}{|c|c|}
\hline Elementos de metadados & Descrição \\
\hline Título & Nome dado ao recurso. \\
\hline Criador & A principal entidade responsável por fazer o recurso. \\
\hline Assunto & $\begin{array}{l}\text { O tópico do recurso. A melhor prática recomendada é usar um } \\
\text { vocabulário controlado. }\end{array}$ \\
\hline Descrição & $\begin{array}{l}\text { Relato sobre o conteúdo do recurso. A descrição pode incluir, mas } \\
\text { não está limitada a: um resumo, um índice, uma representação } \\
\text { gráfica ou um texto livre. }\end{array}$ \\
\hline Publicador & Uma entidade responsável por disponibilizar o recurso. \\
\hline Colaborador & Uma entidade responsável por fazer contribuições para o recurso. \\
\hline Data & $\begin{array}{l}\text { Um ponto ou período de tempo associado a um evento no ciclo de } \\
\text { vida do recurso. }\end{array}$ \\
\hline Tipo & A natureza ou gênero do recurso. \\
\hline Formato & $\begin{array}{l}\text { O formato do arquivo, meio físico ou dimensões do recurso. } \\
\text { Exemplos de dimensões incluem tamanho e duração. }\end{array}$ \\
\hline Identificador & $\begin{array}{l}\text { Uma referência inequívoca ao recurso em um determinado } \\
\text { contexto. }\end{array}$ \\
\hline Fonte & Um recurso relacionado do qual o recurso descrito é derivado. \\
\hline
\end{tabular}


Idioma

Relação

Cobertura

Direitos
O idioma em que o recurso é escrito.

Referência para um recurso relacionado.

Informação sobre os direitos assegurados dentro e sobre o recurso

Informações sobre direitos mantidos dentro e sobre o recurso.

Fonte: Elaborada pelos autores com base em Dublin Core Metadata Initiative, 2014.

\section{Definição das fichas catalográficas}

Partindo do conhecimento teórico adquirido sobre a plataforma Omeka S e o DCMI, avançouse para a definição das fichas catalográficas, atentando-se para o estabelecimento de um método que leva em consideração os dados referentes ao design e a produção das peças.

A definição e estruturação das fichas foi um processo realizado em colaboração com membros da equipe técnica do LPG (André Ferreira, José Tadeu Maia e Sóstenes da Costa) e da seção de materiais iconográficos da FAU (Gisele Ferreira de Brito), além do apoio dos professores Dr. ${ }^{a}$ Clice de Toledo Sanjar Mazzilli, Dr. Francisco Inácio Scaramelli Homem de Melo e Dr. Leandro Manuel Reis Velloso.

As análises realizadas trouxeram sinalizações importantes para o estabelecimento do método catalográfico a ser adotado pelo acervo do LPG. Fruto disso, também se estabelece a divisão do acervo em três categorias: cartazes, publicações e periódicos.

A tabela a seguir sintetiza o detalhamento do conjunto de campos que compõem as fichas de catalogação:

Tabela 2: Síntese do detalhamento dos campos catalográficos

\begin{tabular}{|c|c|c|}
\hline Campos catalográficos & Categorias presentes & Diretrizes de preenchimento \\
\hline Identificador & $\begin{array}{l}\text { Cartazes, publicações e } \\
\text { periódicos }\end{array}$ & $\begin{array}{l}\text { Ctz 1960-001; } \\
\text { Pbl 1975-032; } \\
\text { Prd 2014-013. }\end{array}$ \\
\hline Título & $\begin{array}{l}\text { Cartazes, publicações e } \\
\text { periódicos }\end{array}$ & $\begin{array}{l}\text { Título identificado; } \\
\text { [Título inferido]. }\end{array}$ \\
\hline ISBN & Publicações & ISBN 978-85-92886-01-1. \\
\hline ISSN & Periódicos & ISSN 1018-4783. \\
\hline Autoria & $\begin{array}{l}\text { Cartazes, publicações e } \\
\text { periódicos }\end{array}$ & $\begin{array}{l}\text { Sobrenome, Primeiro nome; } \\
\text { [Sobrenome, Primeiro nome]; } \\
\text { [Autoria não identificada]; } \\
\text { Autoria institucional. }\end{array}$ \\
\hline Edição & Publicações & $2^{\mathrm{a}}$ Edição; $2^{\mathrm{a}}$ Edição revisada; etc. \\
\hline Cidade-Estado & $\begin{array}{l}\text { Cartazes, publicações e } \\
\text { periódicos }\end{array}$ & São Paulo - SP \\
\hline
\end{tabular}




\begin{tabular}{|c|c|c|}
\hline Publicador & $\begin{array}{l}\text { Cartazes, publicações e } \\
\text { periódicos }\end{array}$ & FAUUSP \\
\hline Data & $\begin{array}{l}\text { Cartazes, publicações e } \\
\text { periódicos }\end{array}$ & $\begin{array}{l}\text { Ano. Indicando o maior nível de precisão } \\
\text { possível: } \\
\text { 2018; [2018?]; [201-]; [200-?]; [19--]; [2--- } \\
\text { ?]. }\end{array}$ \\
\hline Paginação & $\begin{array}{l}\text { Cartazes, publicações e } \\
\text { periódicos }\end{array}$ & $\begin{array}{l}96 \mathrm{p} . \\
1 \mathrm{fl}\end{array}$ \\
\hline Ficha técnica & $\begin{array}{l}\text { Cartazes, publicações e } \\
\text { periódicos }\end{array}$ & $\begin{array}{l}\text { Formato; Impressor; Tipos de papel; } \\
\text { Técnicas de impressão; Acabamentos; } \\
\text { Autoria do design; Publicação } \\
\text { (institucional/ estudantil/ independente). }\end{array}$ \\
\hline Resumo & $\begin{array}{l}\text { Cartazes, publicações e } \\
\text { periódicos }\end{array}$ & $\begin{array}{l}\text { Breve texto que contextualiza a obra no } \\
\text { tempo e no espaço e traz informações } \\
\text { interessantes sobre a mesma. }\end{array}$ \\
\hline Direitos & $\begin{array}{l}\text { Cartazes, publicações e } \\
\text { periódicos }\end{array}$ & $\begin{array}{l}\text { Autorização a ser requerida (cartazes e } \\
\text { periódicos); (c) Autor /Autor (Publicações) }\end{array}$ \\
\hline Acervo & $\begin{array}{l}\text { Cartazes, publicações e } \\
\text { periódicos }\end{array}$ & $\begin{array}{l}\text { Acervo LPG FAUUSP / FAUUSP LPG } \\
\text { Collection }\end{array}$ \\
\hline Assuntos & $\begin{array}{l}\text { Cartazes, publicações e } \\
\text { periódicos }\end{array}$ & Vocabulário Controlado da USP \\
\hline Idioma & $\begin{array}{l}\text { Cartazes, publicações e } \\
\text { periódicos }\end{array}$ & MARC List of Languages \\
\hline Tipo & $\begin{array}{l}\text { Cartazes, publicações e } \\
\text { periódicos }\end{array}$ & $\begin{array}{l}\text { Cartaz; Periódico; Apostila; Livro; Folheto; } \\
\text { Catálogo }\end{array}$ \\
\hline Coleção & $\begin{array}{l}\text { Cartazes, publicações e } \\
\text { periódicos }\end{array}$ & $\begin{array}{l}\text { Produção Gráfica FAU; Cartazes; } \\
\text { Publicações; Periódicos. }\end{array}$ \\
\hline
\end{tabular}

Fonte: Elaborada pelos autores.

\section{Manual de Catalogação}

Como resultado final deste trabalho, criou-se o Manual de Catalogação do Acervo do LPG, no intento de formalizar todo o conhecimento levantado, atentando-se ao objetivo de apresentar o método de catalogação de maneira objetiva e de fácil compreensão. A intenção é que esse manual sirva como uma ferramenta didática capaz de guiar o leitor na atividade de catalogação, introduzindo-o de forma sintética às bases teóricas e tecnológicas que fundamentam o banco de dados e trazendo uma definição de cada um dos campos catalográficos.

Ao apresentar essa informação, usa-se de soluções visuais como diagramas e esquemas, que associados ao conteúdo textual, buscam facilitar a compreensão das diretrizes estabelecidas pela pesquisa. A página apresentada a seguir exemplifica o uso desses esquemas: 
Figura 1: Página do manual de catalogação

\section{Publicações}

\section{a) Identificador}

Para manter a organização digital e física do acervo, o primeiro elemento de catalogação que se apresenta é aquilo que chamamos de Identificador. Em suma, o identificador trata-se do elemento catalográfico que irá estabelecer uma relaçấo direta entre os dados preenchidos na ficha e o material concreto, presente no acervo físico. O identificador de publicações apresenta a seguinte estrutura:

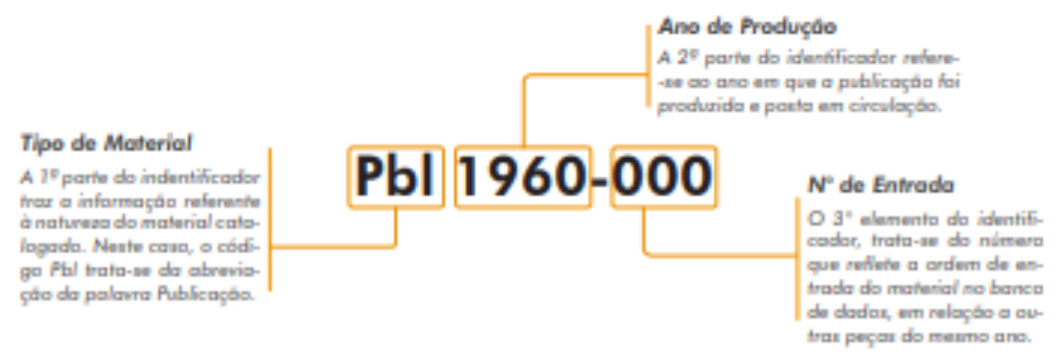

Em casos onde não há certeza sobre a dała da publicaçāo do material, subs:fitui-se $o$ ano e/ou década por asteriscos, a fim de suprimir a informação incerta e manter a dataçăo apenas ao nivel que se pode afirmar com certeza.

\section{Pbl 196*-000 Pbl 19**-000 \\ Ano Incerto \\ Una-ae quanda há certesa da dilcoda de pro-

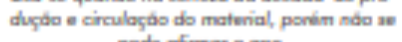 pode afimar a ano. \\ Decoda Incerta \\ Wha-se quando ha certuar do abculo de pro.

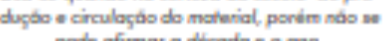 pode afiumar a diccoda e o ana.}

b) Título

Entende-se por fítulo, o nome ou expressáo empregados em relaçāo a uma obra como indicador do seu assunto, ou para individualizar a obra ou trabalho. Se fratando de publicaçōes, o fítulo da obra costuma ser facilmente identificado na capa

\section{Considerações Finais}

Com a conclusão das atividades da pesquisa, pode-se afirmar que os objetivos definidos na ideação do projeto foram alcançados. A criação de fichas catalográficas que contemplam a descrição de fatores relacionados ao design das peças propõe uma forma diferente das até então empregadas na catalogação de materiais iconográficos, sobretudo os materiais 
impressos. A elaboração do manual de catalogação passa adiante essa experiência, consolidando os resultados da pesquisa.

No que tange a valorização da memória da faculdade e da produção do laboratório, o acervo surge como uma importante ferramenta na difusão de uma produção iconográfica genuinamente fauana. Em uma instituição de ensino público do porte da FAU USP, os artefatos que compõem o acervo do LPG materializam os conhecimentos, valores, posicionamentos, debates e inquietudes de uma comunidade acadêmica plural e em constante evolução. Sobretudo quando falamos da produção que emergiu dos esforços das organizações discentes, colocamos em voga a representação material das reflexões de uma geração em formação intelectual.

\section{Referências bibliográficas}

ALVES, M. das D. R.; SOUZA, M. I. F.. Estudo de correspondência de elementos metadados: Dublin Core e Marc 21. Revista Digital de Biblioteconomia e Ciência da Informação [online]. Campinas, v. 4, n. 2, p. 20-38, jan./jun. 2007.

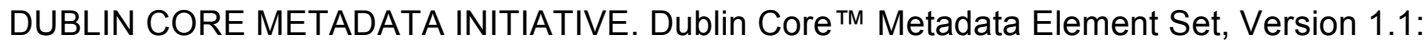
Reference Description. Estados Unidos, 2014. Disponível em:

https://www.dublincore.org/specifications/dublin-core/dces/. Acesso em: 8 mai. 2021.

GRÁCIO, José Carlos Abbud. Metadados para a descrição de recursos da Internet: o padrão Dublin Core, aplicações e a questão da interoperabilidade. 2002. 127f. Dissertação (Mestrado em Ciência da Informação) - Faculdade de Filosofia e Ciências, Universidade Estadual Paulista, Marília. 2002.

SHINTAKU, Milton et al. Guia do usuário do Omeka. Brasília, 2018.

\section{Sobre os autores}

Vinícius de Souza Lima, FAU USP, Brasil <lima.v.s@usp.br>

Clice Toledo de Sanjar Mazzilli, Dr. ${ }^{a}$, FAU USP, Brasil <clice@usp.br> 